\title{
Beta-delayed gamma spectra in CENDL-3.2
}

\author{
Shuyu Zhu ${ }^{1}$, Xiaoxue Zhao ${ }^{1,2}$, Nengchuan Shu ${ }^{1 *}$, Haicheng W ${ }^{1}$, Lin Liu $^{2 *}$, Yongjing Chen ${ }^{1}$, Lile Liu $^{1}$ \\ ${ }^{1}$ China N uclear Data Centre, 102413, B eijing, China \\ ${ }^{2}$ College of physical science and technology, Shenyang Normal University, 110034, Shenyang, China
}

\begin{abstract}
A new program is developed to compute the beta delayed fission gamma spectrum, and applied to compute the spectra of $n+{ }^{235} \mathrm{U},{ }^{239} \mathrm{Pu}$ and ${ }^{241} \mathrm{Pu}$ fissions wherein the recent nuclear database is adopted. The results show that most spectra are well in agreement with the data from ENDF/B -VII.0 library, and some are quite different, which should be caused by the improvement of the nuclear database.
\end{abstract}

\section{Introduction}

The beta delayed fission gamma spectrum (hereafter called BDFG), also named the delayed gamma source function in ENDF formats manual [1], is formed by the emitted gammas during the fission products beta decay, which could be used in such as reactor shielding, spent fuel decay heat and fission experiment simulation etc, and also could check the product fission yields compared to their measured gamma spectra.

BDFG is stored in ENDF- 6 format with M T $=460$ and $M F s=1,12,13$, standing for the normalization coefficient, normalized spectrum as function of time, and angular distribution, respectively. There are only 2 sets of BDFG of $n+{ }^{235} \mathrm{U}$ and ${ }^{239} \mathrm{Pu}$ fission in ENDF/B-VII.1 library, which should be contributed in 2004 or so [2].

The motivation of this work is to develop a different method with Ref. [2] to calculate the BDFG of $n+{ }^{235} U$ and ${ }^{241} \mathrm{Pu}$, make update and supplement for the BDFG library with new nuclear database.

\section{Calculation Method}

The beta delayed fission gamma spectrum, is defined as the gamma number emitted per unit time per unit gamma energy after a certain fission event [1],

$$
S_{\gamma}\left(t, E_{\gamma}\right) \equiv \frac{d^{2} n}{d E_{\gamma} d t}\left(t, E_{\gamma}\right)
$$

And it could be calculated as the following formula,

$$
S_{\gamma}\left(t, E_{\gamma}\right)=\int_{\mathrm{t}}^{\mathrm{t}+1} \sum_{\mathrm{i}, \mathrm{j}} \delta\left(E-E_{\gamma}\right) \lambda_{\mathrm{i}} n_{\mathrm{i}}(t) I_{\mathrm{i}, \mathrm{j}}\left(E_{\gamma}\right) \mathrm{d} t
$$

where $t$ is the time following fission at which the gamma is emitted, $E_{\gamma}$ the emitted gamma energy, $\lambda_{\mathrm{i}}$ the decay constant of nuclide $i, I_{\mathrm{i}, \mathrm{j}}$ the intense of $j^{\text {th }}$ gamma of the nuclide $i, n_{\mathrm{i}}$ is the abundance of nuclei $i$, which is a function time $t$, could be calcuated by resloving the ordinary differential equations,

$$
\begin{gathered}
\frac{\mathrm{d} n_{\mathrm{i}}(t)}{\mathrm{d} t}=-\lambda_{\mathrm{i}} n_{\mathrm{i}}(t)+\sum_{\mathrm{j}} \lambda_{\mathrm{j} \rightarrow \mathrm{i}} n_{\mathrm{j}}(t), \\
n_{\mathrm{i}}(0)=\mathrm{y}_{\mathrm{i}}
\end{gathered}
$$

where the first item on the left of eq. (3) is nuclide $i$ decaying to others, and the second item is the precursor nuclide $j$ decay into this $i$ nuclide. This equation could be calculated with burn-up codes such as CINDER [3] or Origen[4]. The inital numbers at $t=0$ are given with the independent yields in eq. (4).

In this work, a gamma summation code named FP.pl (Fission Photon) is created. It reads the number $n_{i}(t)$ of fission products from the calculation result of eqn (3) and (4), compute the individual spectrum as a function of time $t$ for each gamma emitted. A nd then make the summation of all the individual spectra to produce the total BDFG, S $\gamma$. Fission yields are taken from ENDF/B-VII.1 and decay data from NuDat (2017) [5].

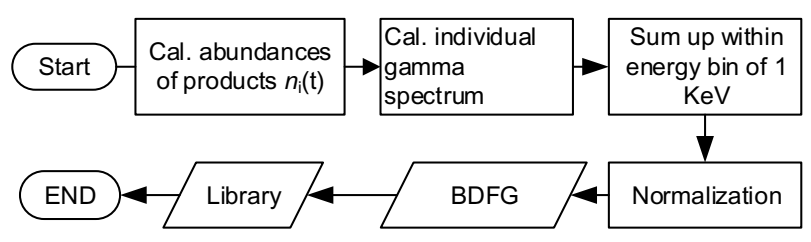

Fig. 1. The main flow of FP.pl code.

Given the parameters of a fission experiment, gamma counts could be simulated based upon the BDFG, $S_{\gamma}$ as

$$
\begin{aligned}
& N_{\gamma}\left(E_{\gamma}, t_{\mathrm{c}} \rightarrow t_{\mathrm{c}}+t_{\mathrm{d}}\right)= \\
& \quad f\left(E_{\gamma}\right) \int_{t_{\mathrm{c}}}^{t_{\mathrm{c}}+t_{\mathrm{d}}} \int_{0}^{t_{\mathrm{r}}} f_{\mathrm{r}}\left(t_{\mathrm{r}}\right) S_{\gamma}\left(t+t_{\mathrm{r}}, E_{\gamma}\right) d t_{\mathrm{r}} d t,
\end{aligned}
$$

where $t_{\mathrm{c}}, t_{\mathrm{d}}$ are the cooling and detecting times resp., $f\left(E_{\gamma}\right)$ the factor including detector efficience, dead time corretion, gamma absorb correction, geometric correction, conversion of calcualted count to measured count etc. $t_{\mathrm{r}}$ the radiating time of sample, and $f_{\mathrm{r}}\left(t_{\mathrm{r}}\right)$ is the fission rate function, these paramters are provided by the exprimenter. 
To verify the code FP.pl, BDFGs of $n+{ }^{235} \mathrm{U}$ are calculated and compared with those in ENDF/B-VII.1. They agree very well at most energies such as shown in Fig. 2 and Fig.3, but some do not, as shown in Fig. 4 which should be caused by the improvement of the new nuclear data base in this work.

Simulation of a fission experiment is performed with eq. (5), the result is illustrated in Fig. 5, the calculated gamma counts are in good agreement with measured counts, where '138Cs' at $1009.8 \mathrm{keV}$ should be combined with the gamma at $1010 \mathrm{keV}$ emitted from ${ }^{142} \mathrm{La}$. This experiment was carried out in China Nuclear Data Centre.

The above comparisons verified the FP.pl code, and showed the present results are improved with new nuclear database.

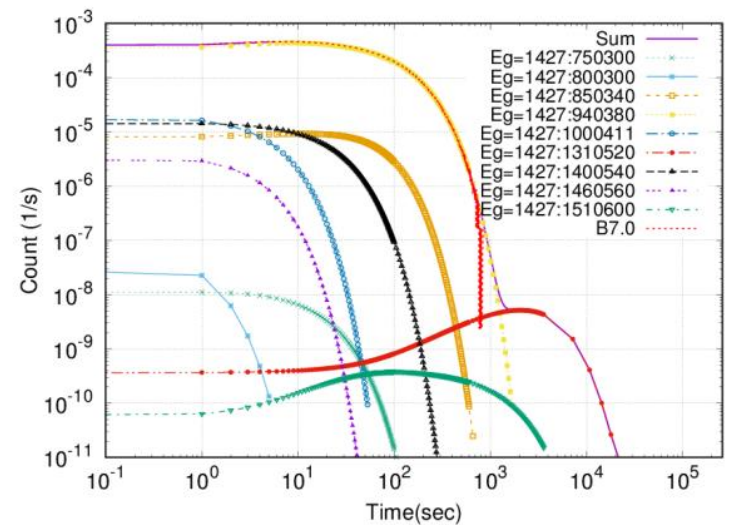

Fig. 2. Calculated BDFGs at $E_{\gamma}=1427 \mathrm{keV}$, compared with that in ENDF/B-VII.0 for $\mathrm{n}_{\mathrm{th}}+{ }^{235} \mathrm{U}$ fission. The legend such as ' $1427: 750300$ ' denotes the $Y(1427 \mathrm{KeV})$ emitted from the decay of nuclide $A^{*} 1000+Z * 100+$ Isomer $(A=75, \quad Z=30$, Isomer $=0$ )
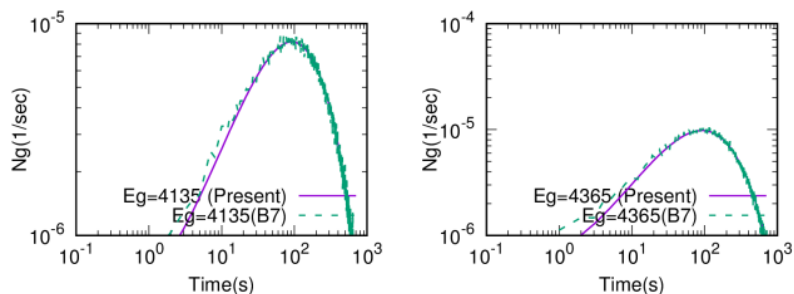

Fig. 3 Calculated BDFGs at $\mathrm{E}_{\gamma}=4135$ and $4365 \mathrm{keV}$ compared with those in ENDF/B-VII.1 for $\mathrm{n}_{\mathrm{th}}+{ }^{235} \mathrm{U}$ fission.
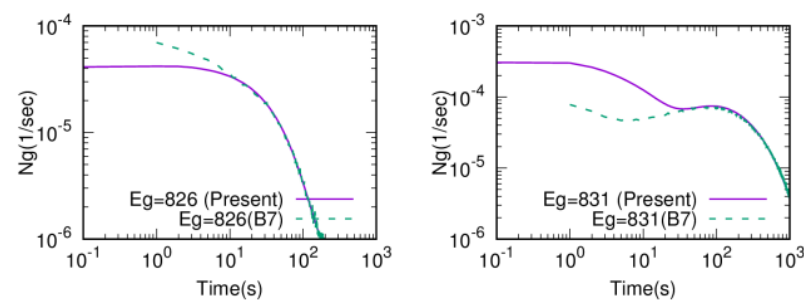

Fig. 4 Calculated BDFGs at $E_{\gamma}=826$ and $831 \mathrm{keV}$ compared with those in ENDF/B-VII.1 for $\mathrm{n}_{\mathrm{th}}+{ }^{235} \mathrm{U}$ fission.

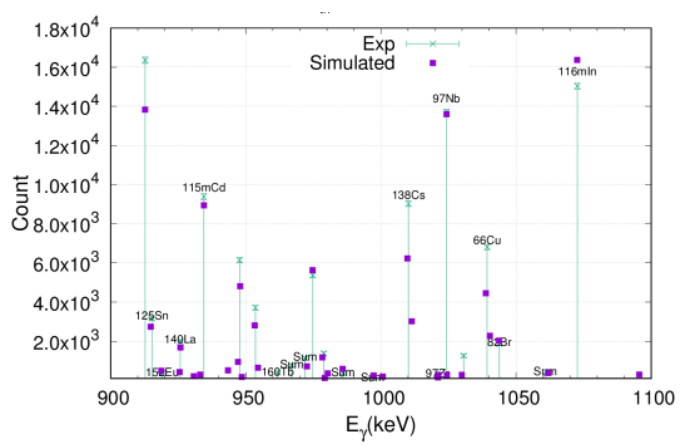

Simulated gamma counts compared with the measured.

Fig. 5 .

\section{BDFG calculation of $n+{ }^{241} P u$ fission}

The beta delayed fission gamma spectra of $n+{ }^{241} \mathrm{Pu}$ are calculated with incident neutron of thermal and fission spectrum. Part of the results of $n_{\mathrm{th}}+{ }^{241} \mathrm{Pu}$ are shown in Fig.6, which counts (coefficients) are larger than 0.001 at variant energy regions around 500, 1000, 1500 and 2000 $\mathrm{keV}$. There are about 50 coefficients are large than 0.01 and listed in Table. 1.
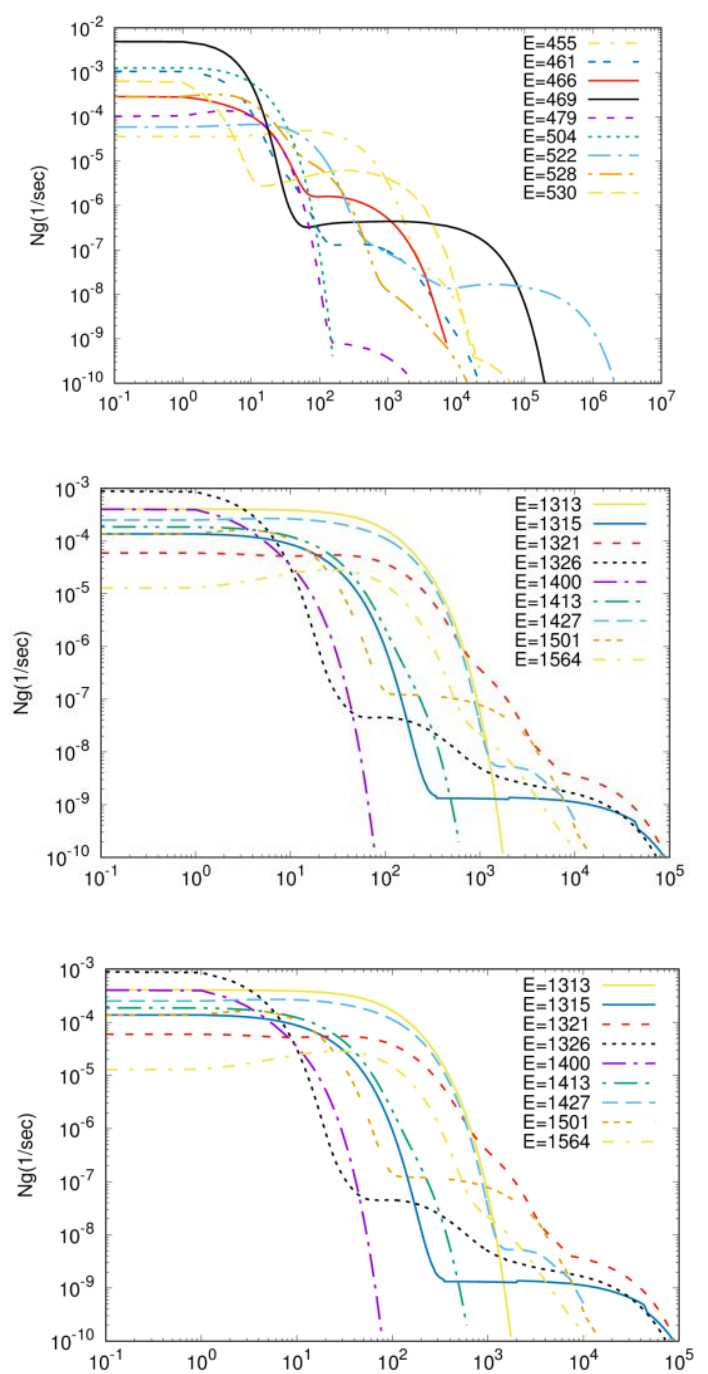


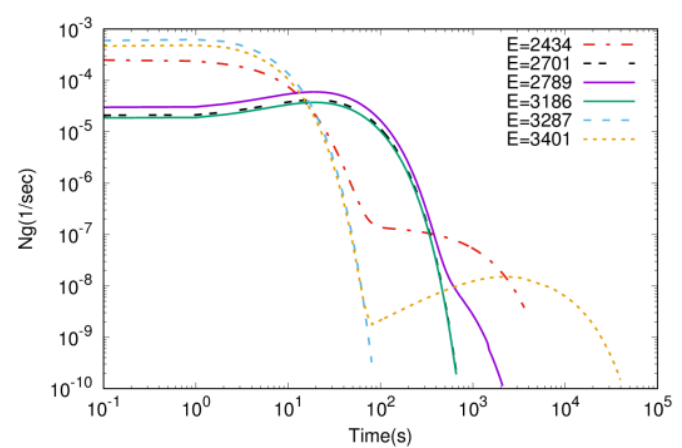

Fig. 6. The BDFG of $\mathrm{n}_{\mathrm{th}}+{ }^{241} \mathrm{Pu}$ fission at variant energies as functions of the decay time.

The integrals of BDFG are calculated over the gamma energy regions of 0-6950, 1000-2000, 2000-3000, 30004000, 4000-6950 keV. As shown in Fig.7, the total gamma count rate at zero time is about 0.2 per second, this hints that there is 0.02 beta delayed gamma emitted in the first second after one fission. The others are about 0.03 , 0.002 and 0.0002 per second (Fig.4), contributing about $15 \%, 1 \%$ and $0.1 \%$ to the total. And the BDFG within 0 $1000 \mathrm{keV}$ contributes most of the total gammas, about $84 \%$.

The total gamma number decreased rapidly during 1 100 seconds, about $10^{4}$ seconds later, it is less than $0.1 \%$ of the primary counts at zero time.

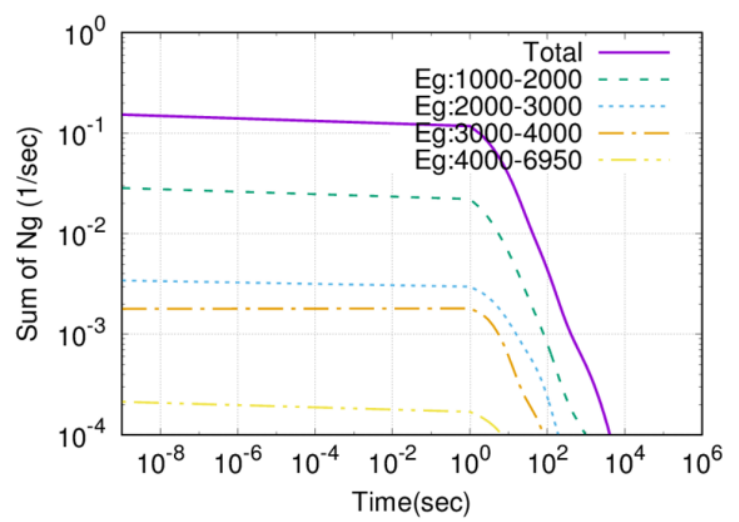

Fig. 7. Integral of BDFG over variant energy regions as functions of the decay time for $\mathrm{n}_{\mathrm{th}}+{ }^{241} \mathrm{Pu}$ fission.

Table 1. BDFG Coefficients $(>0.01)$ of $n+{ }^{241} \mathrm{Pu}$ fissions.

\begin{tabular}{|c|c|c|c|}
\hline $\mathbf{E} \boldsymbol{\gamma}(\mathbf{K e V})$ & $\mathbf{E n}=\mathbf{T}$ & $\mathbf{E n}=\mathbf{F}$ & $\mathbf{T} / \mathbf{F}$ \\
\hline 2 & $1.91 \mathrm{E}-02$ & $1.96 \mathrm{E}-02$ & 1.00 \\
\hline 13 & $1.31 \mathrm{E}-02$ & $1.38 \mathrm{E}-02$ & 1.10 \\
\hline 17 & $9.22 \mathrm{E}-02$ & $9.41 \mathrm{E}-02$ & 1.00 \\
\hline 18 & $7.75 \mathrm{E}-02$ & $7.94 \mathrm{E}-02$ & 1.00 \\
\hline 19 & $1.87 \mathrm{E}-02$ & $1.84 \mathrm{E}-02$ & 0.98 \\
\hline 20 & $1.44 \mathrm{E}-02$ & $1.44 \mathrm{E}-02$ & 1.00 \\
\hline 32 & $1.17 \mathrm{E}-02$ & $1.22 \mathrm{E}-02$ & 1.00 \\
\hline 33 & $1.17 \mathrm{E}-02$ & $1.14 \mathrm{E}-02$ & 0.97 \\
\hline 36 & $1.63 \mathrm{E}-02$ & $1.68 \mathrm{E}-02$ & 1.00 \\
\hline 43 & $1.29 \mathrm{E}-02$ & $1.34 \mathrm{E}-02$ & 1.00 \\
\hline
\end{tabular}

\begin{tabular}{|c|c|c|c|}
\hline 68 & $2.95 \mathrm{E}-02$ & $2.98 \mathrm{E}-02$ & 1.00 \\
\hline 85 & $1.44 \mathrm{E}-02$ & $1.58 \mathrm{E}-02$ & 1.10 \\
\hline 97 & $1.64 \mathrm{E}-02$ & $1.52 \mathrm{E}-02$ & 0.93 \\
\hline 119 & $8.71 \mathrm{E}-03$ & $1.08 \mathrm{E}-02$ & 1.20 \\
\hline 121 & $1.64 \mathrm{E}-02$ & $1.71 \mathrm{E}-02$ & 1.00 \\
\hline 122 & $1.98 \mathrm{E}-02$ & 2.19E-02 & 1.10 \\
\hline 137 & $2.94 \mathrm{E}-02$ & $2.74 \mathrm{E}-02$ & 0.93 \\
\hline 161 & $1.12 \mathrm{E}-02$ & $1.01 \mathrm{E}-02$ & 0.90 \\
\hline 197 & $1.61 \mathrm{E}-02$ & $1.42 \mathrm{E}-02$ & 0.88 \\
\hline 211 & $1.17 \mathrm{E}-02$ & $1.20 \mathrm{E}-02$ & 1.00 \\
\hline 258 & $1.37 \mathrm{E}-02$ & $1.30 \mathrm{E}-02$ & 0.95 \\
\hline 270 & $2.92 \mathrm{E}-02$ & 2.97E-02 & 1.00 \\
\hline 276 & $1.44 \mathrm{E}-02$ & $1.50 \mathrm{E}-02$ & 1.00 \\
\hline 296 & $3.34 \mathrm{E}-02$ & $3.58 \mathrm{E}-02$ & 1.10 \\
\hline 381 & $1.68 \mathrm{E}-02$ & $1.42 \mathrm{E}-02$ & 0.85 \\
\hline 397 & $3.42 \mathrm{E}-02$ & 3.39E-02 & 0.99 \\
\hline 400 & $1.12 \mathrm{E}-02$ & $1.11 \mathrm{E}-02$ & 0.99 \\
\hline 447 & $9.58 \mathrm{E}-03$ & $1.03 \mathrm{E}-02$ & 1.10 \\
\hline 469 & $2.98 \mathrm{E}-02$ & 2.77E-02 & 0.93 \\
\hline 504 & $1.60 \mathrm{E}-02$ & $1.59 \mathrm{E}-02$ & 0.99 \\
\hline 535 & $2.96 \mathrm{E}-02$ & $2.82 \mathrm{E}-02$ & 0.95 \\
\hline 541 & $1.33 \mathrm{E}-02$ & $1.31 \mathrm{E}-02$ & 0.98 \\
\hline 546 & $2.58 \mathrm{E}-02$ & $2.40 \mathrm{E}-02$ & 0.93 \\
\hline 551 & $1.25 \mathrm{E}-02$ & $1.34 \mathrm{E}-02$ & 1.10 \\
\hline 588 & $1.41 \mathrm{E}-02$ & $1.19 \mathrm{E}-02$ & 0.84 \\
\hline 593 & $1.52 \mathrm{E}-02$ & $1.42 \mathrm{E}-02$ & 0.93 \\
\hline 602 & $2.26 \mathrm{E}-02$ & $2.09 \mathrm{E}-02$ & 0.92 \\
\hline 603 & $1.08 \mathrm{E}-02$ & $1.09 \mathrm{E}-02$ & 1.00 \\
\hline 724 & $1.13 \mathrm{E}-02$ & $1.16 \mathrm{E}-02$ & 1.00 \\
\hline 809 & $1.85 \mathrm{E}-02$ & $2.06 \mathrm{E}-02$ & 1.10 \\
\hline 1103 & $1.54 \mathrm{E}-02$ & $1.40 \mathrm{E}-02$ & 0.91 \\
\hline 1222 & $1.42 \mathrm{E}-02$ & $1.22 \mathrm{E}-02$ & 0.86 \\
\hline 1313 & $3.16 \mathrm{E}-02$ & $2.85 \mathrm{E}-02$ & 0.90 \\
\hline 1427 & $2.11 \mathrm{E}-02$ & $2.10 \mathrm{E}-02$ & 1.00 \\
\hline 1632 & $1.70 \mathrm{E}-02$ & $1.82 \mathrm{E}-02$ & 1.10 \\
\hline 1750 & $1.39 \mathrm{E}-02$ & $1.10 \mathrm{E}-02$ & 0.79 \\
\hline
\end{tabular}

\section{Build of BDFG library}

The beta delayed fission gamma spectra are converted to ENDF/B-VI format as descripted in ENDF-6 format manual which MT is 460, and there are 3 files $M F=1,12$ and 13. The general information is described in Table 2 for the case of ${ }^{241} \mathrm{Pu}$.

$\mathrm{MF}=1$ of $\mathrm{MT}=460$ is the normalized $\mathrm{BDFG}$, as shown in Table 3. The first column data in line 2 and line 11 are the gamma energies in $\mathrm{eV}$ (here are 6.95E6 and 6.794E6). Line 4-10 and 13-19 are the two normalized BDFGs with 2 data (time, count) in group, the group numbers are ' 20 ' and ' 19 ' as indicated in line 3 and 12, respectively. 
$\mathrm{MF}=12$ of $\mathrm{MT}=460$ is the normalization coefficients, as shown Table 4. Line 6 indicates the energy in the first column (here is 6.95E6) corresponding to that one in $\mathrm{MF}=1$. Line 8-9 are the 6 groups of the coefficients; each group contains two data of the incident neutron energy in $\mathrm{eV}$ and coefficient in $1 / \mathrm{sec} . \mathrm{MF}=14$ is the angular distribution. More detail information could be found in the ENDF- 6 manual. The database of $n+{ }^{235} \mathrm{U},{ }^{239} \mathrm{Pu}$ and ${ }^{241} \mathrm{Pu}$ BDFGs have been checked and complied into CENDL-3.2, the main text lines are listed in Table 2 for the case of ${ }^{241} \mathrm{Pu}$.

Table 2. Beta-delayed fission gamma spectrum of $n+{ }^{241} \mathrm{Pu}$ fission in ENDF-6 format (MF=1, MT=451, general information)

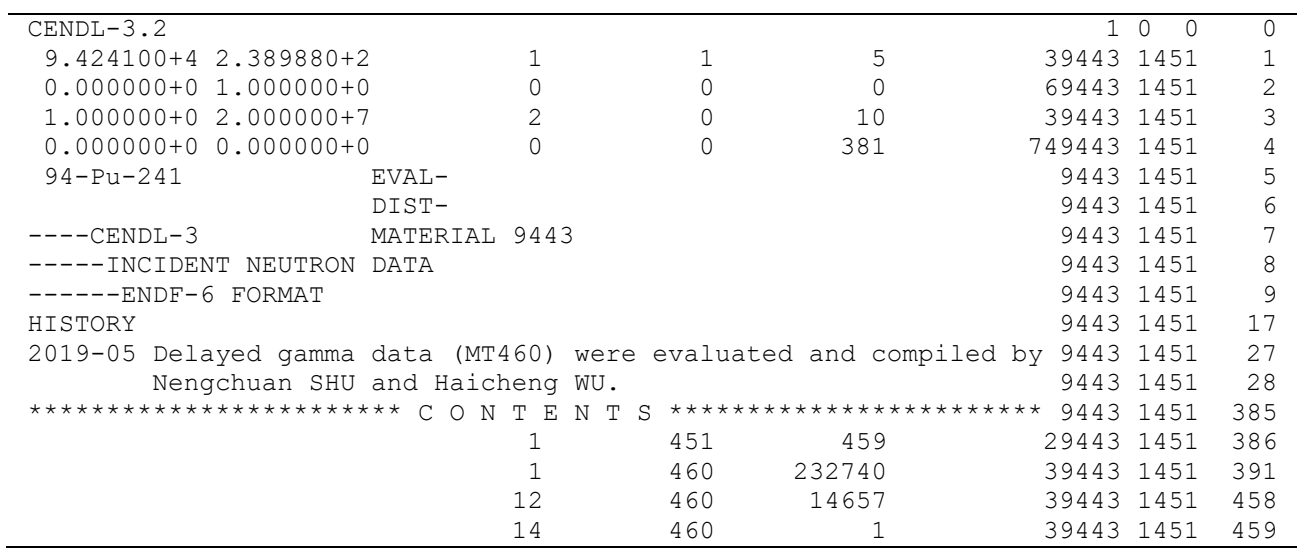

Table 3. Main text lines of beta-delayed fission gamma spectrum of $n+{ }^{241} \mathrm{Pu}$ fission in ENDF-6 format $(\mathrm{MF}=1, \mathrm{MT}=460$, normalized beta-delayed fission gamma spectrum as function of time)

\begin{tabular}{|c|c|c|c|c|c|c|c|}
\hline $9.42390+04$ & $2.36999+02$ & 1 & 0 & 3666 & 09437 & 1460 & 1 \\
\hline $6.95000+06$ & 0 & 1 & 0 & 1 & 209437 & 1460 & 2 \\
\hline 20 & 4 & & & & 9437 & 1460 & 3 \\
\hline 0 & $3.79723-01$ & $1.00000+00$ & $2.35728-01$ & $2.00000+00$ & $1.46153-019437$ & 1460 & 4 \\
\hline $3.00000+00$ & $9.06151-02$ & $0000+00$ & $317-02$ & $5.00000+00$ & $8-029437$ & 1460 & 5 \\
\hline $6.00000+00$ & $2.15965-02$ & $7.00000+00$ & $1.33900-02$ & $8.00000+00$ & -039437 & 1460 & 6 \\
\hline $9.00000+00$ & $5.14731-03$ & $1.00000+01$ & $3.19146-03$ & $1.10000+01$ & -039437 & 1460 & 7 \\
\hline $1.20000+01$ & $1.22697-03$ & $00+01$ & $25-04$ & $00+01$ & $5-049437$ & 1460 & 8 \\
\hline $1.50000+01$ & $2.92629-04$ & $1.60000+01$ & $1.81533-04$ & $1.70000+01$ & $3-049437$ & 1460 & 9 \\
\hline $1.80000+01$ & $6.99471-05$ & $1.90000+01$ & $4.34697-05$ & & 9437 & 1460 & 10 \\
\hline $6.79400+06$ & 0 & 2 & 0 & 1 & 199437 & 1460 & 11 \\
\hline 19 & 4 & & & & 9437 & 1460 & 12 \\
\hline 0 & $3.79740-01$ & $0+00$ & $39-01$ & $2.00000+00$ & $9-019437$ & 1460 & 13 \\
\hline $3.00000+00$ & $9.06190-02$ & $4.00000+00$ & $5.61842-02$ & $5.00000+00$ & $3.48344-029437$ & 1460 & 14 \\
\hline
\end{tabular}

Table 4. Main text lines of beta-delayed fission gamma spectrum of $n+{ }^{241} \mathrm{Pu}$ fission in ENDF- 6 format (MF=12, MT=460, normalization coefficient)

\begin{tabular}{|c|c|c|c|c|c|c|}
\hline $9.42390+04$ & $2.36999+02$ & 1 & 0 & 3665 & 0943712460 & 1 \\
\hline $0.000000+0$ & $0.000000+0$ & 0 & 0 & 1 & 6943712460 & 2 \\
\hline 6 & 2 & & & & 943712460 & 3 \\
\hline $1.00000-05$ & $2.19709+00$ & $1.00000+05$ & $2.19709+00$ & $1.00000+05$ & $2.19709+00943712460$ & . \\
\hline $7.00000+06$ & $2.19709+00$ & $7.00000+06$ & $2.19709+00$ & $2.00000+07$ & $2.19709+00943712460$ & 5 \\
\hline $6.95000+06$ & $0.00000+00$ & 0 & 2 & 1 & 6943712460 & 6 \\
\hline $\begin{array}{r}6 \\
1.00000-05\end{array}$ & $\begin{array}{r}2 \\
3.54224-08\end{array}$ & $1.00000+05$ & $3.54224-08$ & $1.00000+05$ & $\begin{array}{r}943712460 \\
3.54224-08943712460\end{array}$ & 7 \\
\hline
\end{tabular}

\section{Remarks}

A new code FP.pl has been created and verified calculate the beta-delayed fission gamma spectrum with recent updated nuclear database. The beta-delayed fission gamma spectrum of $\mathrm{n}+{ }^{235} \mathrm{U},{ }^{239} \mathrm{Pu}$ and ${ }^{241} \mathrm{Pu}$ fissions are calculated and complied into CENDL-3.2.

This work was supported by national nature science foundation of China (No. 11790320, 11790323, 11790324, 11790325, U1867213), the continuous Basic Scientific Research Project (No. WDJC-2019-09)

\section{References}

[1] A. Trkov, M. Herman and D. A. Brown, ENDF-6 Formats Manual, Report BNL-90365-2009 Rev.1(2010). p.49.

[2] J. Pruet et al., N ucl. Inst. M eth. B 222, 403 (2004).

[3] W. W ilson, S. Cowell, T. England et al. A Manual for CINDER'90 Version 07.4 Codes and Data [R]. LoS A lamos National L aboratory, LA -UR-07-8412.

[4] G. Croff, A User's Manual for the ORIGEN2 Computer Code. ORNL/TM-7175, Oak Ridge $\mathrm{N}$ ational Laboratoly, 1980.

[5] http://www.nndc.bnl.gov 